\title{
The Time Equation Explaining Equations in Physics and Economics
}

\author{
Poramest Boonsri
}

\begin{abstract}
Researchers know a little about time. If they could not find where time was, they could not study it. The objective of this study was to find where time was. Any numbers in three principal axes were used to be data. Galileo's concept of the relationship among distance, speed, and time was used to find a position of a value of time in any number lines in a three-dimensional body. Mathematical derivative was used to prove the positions of the values of time. The investigation found that time is in all number lines including three principal axes. Also, the time equation can be used to calculate the exact position of any values of time in the line. The equation can be used to explain equations in science such as equations of Newton, Einstein, and Plank, and social science such as equations of consumption and saving in macroeconomics. If researchers use the time equation to explain $N$ equations, then a time value can get at least $N$ variables of $N$ equations. The speed of calculation will increase. The equation will be used to open new characteristics about time and others because mathematicians use numbers to represent everything in nature.
\end{abstract}

Index Terms: time equation, equations, physics, economics

\section{INTRODUCTION}

In 1905, Einstein explained the new characteristic of time as a relative value, not an absolute value. The time dimension depends on a frame of reference. The traveling of twins was used to explaind the time dimension depending on the frame of reference. While the first one in the frame of reference as the rocket was traveling in space with high speed, another was in the earth. Both of them are living in the different frames of reference. Ten years later, they met each other and found that the first one was younger than the second one.

When we tried to study what time was, we always used the 4-D Minkowski's model of space-time to explain the Einstein's theory of Special Relativity [1]. Minkowski concluded that positive numbers have positive time values, and negative numbers have negative time values as well. If time values are negative in past Light Cone of Minkowski, then time traveling can be possible. The time dimension in a three-dimensional body is among three principal axes with the mathematical model as $(x, y, z, t)$. Notably, there is no time value in the three principal axes.

The model still was used in many books. For example, in 1988, Stephen Hawking still used 4-D Minkowski's model to explain about time. He created the new phrase "arrows of time" to explain time in three kinds: Thermodynamics,

Revised Manuscript Received on September 22, 2019.

Poramest Boonsri, Bansomdejchaopraya Rajabhat University, Bangkok, Thailand psychology, and the expansion of the universe. For example, when the time passes, the energy from foods would decay. Also, when the universe expands, objects in the sky will increase the lack of discipline [2]. Notably, the arrow of time is still not the direction of the time dimension. Time still is scalar, which has not any direction. In 1995, Paul Davies wrote his book "About Time." He concluded that the time dimension is a missing link that scientists have never known [3].

Besides, Michio Kaku, American theoretical physicists, who mentioned about the existence of one-inch equation that can explain all forces in physics which concern Theory of Everything (TOE) [4]. Since in 1987 when Kaku predicted TOE in his book "Beyond Einstein", nobody had found. The little physicist believed there was the theory which united four fundamental forces in nature together: (1) Weak force, (2) Strong force, (3) electromagnetic force, and (4) Gravity force. The theory might decrease the time to study physics from 20 years to four years in the university. He expected that the equation would push physics in advanced level which physicists had never found before because the theory was a missing link no one found [5].

When having linked the two previous aspects together, we found that the time is a natural link which links everything together. If the new knowledge about time was discovered, we might find something new in science such as physics and social science such as economics.

\section{DATA AND METHODOLOGY}

Numbers in three principal axes were used to be data. Galileo's concept of relationship among distance, speed, and time is used to find a position of a time value in any number lines in three-dimensional body. Derivative was used to prove the positions of the time values.

\section{RESULTS}

\section{A. Proof of existence of time in a number line}

The first step that researchers have to do is finding where time is because if researchers could not find it, they could not study it. Whenever they drew a line, they had to spend time. "Is the time dimension in a number in a line?" Galileo's concept about the relation among distance, speed, and time was used first. Later, Newton used his derivative to explain velocity $(\mathrm{v}=\mathrm{dS} / \mathrm{dt})$; as a result, the relationship among the three dimensions was explained again as $S=v t$, where $S$ represents the distance; $\mathrm{v}$ represents the velocity of 
moving (or speed); and trepresents the time value of moving.

When we draw a line, two factors affecting the length (or distance) are: (1) the velocity of drawing, and (2) the time we use to draw the line called the value of time or the time value. Given the time value, if a drawer uses a higher velocity to draw, then the length of the line will be longer. Similarly, given velocity of drawing, if the value of time is spent more, the length of the line will be longer as well. In other words, the concept used to solve the hypothesis about a time value matching with a number in a number line is the Galileo's concept, $\mathrm{S}=\mathrm{vt}$, where $\mathrm{S}$ represents the distance of the line, $\mathrm{v}$ represents the velocity of drawing the line, and $t$ represents the time value used to draw the line.

In a three-dimensional body, there are three principal axes representing the width, the length, and the thickness, which are subset of distance.

With derivative mathematics, we found something new: first, the distance depends on the only time value, $S=f(t)$. When we increase a longer time, the distance will be longer. The line depends on the only value of time. In present, many scientists believe that distance depends on the speed of moving and the value of time; however, the previous proof showed the velocity is the change of distance per the change of time as a unit. Besides, distance is still positive, so the value of time always is positive. See how to prove as follows [6].

From the equation of distance:

$$
\begin{aligned}
& =\mathrm{vt} \\
& \text { S } \\
& \text { dS } \quad=\frac{d(v t)}{d t} \\
& \text { Given } \mathrm{v}=\text { constant } \\
& \frac{\mathrm{dS}}{\mathrm{dt}} \\
& =\frac{\mathrm{vd}(\mathrm{t})}{\mathrm{dt}}+\frac{\mathrm{td}(\mathrm{v})}{\mathrm{dt}} \\
& =\mathrm{v}(1)+\mathrm{t}(0) \\
& =\mathrm{v} \\
& =\left(\frac{d S}{d t}\right) \mathrm{t} \\
& =0+\left(\frac{\mathrm{dS}}{\mathrm{dt}}\right) \mathrm{t}
\end{aligned}
$$

The relation between $\mathrm{S}$ and $\mathrm{t}$ is linear, or degree of $\mathrm{S}$ and $\mathrm{t}$ is one; as the result,

$$
\begin{array}{ll}
\frac{\mathrm{dS}}{\mathrm{dt}} & =\left(\frac{\Delta S}{\Delta \mathrm{t}}\right) \\
\mathrm{S} & =0+\left(\frac{\Delta s}{\Delta t}\right) \mathrm{t} \\
\mathrm{S} & =\mathrm{f}(\mathrm{t})
\end{array}
$$

\section{B. Finding time in three principal axes}

All three principal axes depend on the only time value as well with the same method of proof: $\mathrm{x}=\mathrm{g}(\mathrm{t}) ; \mathrm{y}=\mathrm{h}(\mathrm{t}) ; \mathrm{z}=\mathrm{i}$ $(t)$. Notably, time always is in three principal axes or $\left(x_{t}, y_{t}\right.$, $\mathrm{z}_{\mathrm{t}}$ ), not following Minkowski's 4D model, $(\mathrm{x}, \mathrm{y}, \mathrm{z}, \mathrm{t})$.

\section{Naming points in three principal axes}

At the same point of three lines, three drawers may create different names. For example, at $\mathrm{S}=1$, three drawers No.one, two, and three are determining three numbers as 100,10 , and 1 with different kinds of unit, respectively. As a result, at $\mathrm{S}=4$, the three drawers are giving the number as 400, 40, and four respectively. With the concept, we can find five dimensions concerning a point.

If we call " $x$ " as a determined number, then we can write the relation among $S, x, R, v$, and $t$ as follow:

$\frac{|x|}{R_{x}}=S_{x}=v_{x} t_{x}=\left(\frac{d S_{x}}{d t_{x}}\right) t_{x}=\left(\frac{\Delta S_{x}}{\Delta t_{x}}\right) t_{x}$

If we call " $y$ " as a determined number, then we can write the relation among $S, y, R, v$, and $t$ as follow:

$\frac{|y|}{\mathrm{R}_{y}}=\mathrm{S}_{\mathrm{y}}=\mathrm{v}_{\mathrm{y}} \mathrm{t}_{\mathrm{y}}=\left(\frac{\mathrm{dS}_{\mathrm{y}}}{\mathrm{dt} \mathrm{t}_{\mathrm{y}}}\right) \mathrm{t}_{\mathrm{y}}=\left(\frac{\Delta \mathrm{S}_{y}}{\Delta \mathrm{t}_{y}}\right) \mathrm{t}_{\mathrm{y}}$

If we call " $z$ " as a determined number, then we can write the relation among $S, z, R, v$, and $t$ as follow:

$\frac{|z|}{\mathbb{R}_{z}}=S_{z}=v_{z} t_{z}=\left(\frac{d S_{z}}{d t_{z}}\right) t_{z}=\left(\frac{\Delta S_{z}}{\Delta t_{z}}\right) t_{z}$

Given $\mathrm{N}$ as a determined number. We can write the relation among $\mathrm{S}, \mathrm{N}, \mathrm{R}, \mathrm{v}$, and $\mathrm{t}$ as follow:

$$
\frac{|\mathbb{N}|}{\mathbb{R}}=\mathrm{S}=\mathrm{vt}=\left(\frac{\mathrm{dS}}{\mathrm{dt}}\right) \mathrm{t}=\left(\frac{\Delta S}{\mathrm{dt}}\right) \mathrm{t}
$$

This equation (5) is one of the most essential aspects of time concerning determined numbers. Mathematicians determine two kinds of numbers on the six sides of three principal axes, but the relationship between all numbers (with positive and negative) and distance is still positive because the distance and the value of $\mathrm{R}$ always are positive.

For example, the following Fig. 1 shows five values of $\mathrm{N}$ as $100,200,300,400$, and 500 respectively with the unit as tons. The distances from the origin to those five determined numbers are 20,40,60, 80, and 100 inches long respectively. The velocity of drawing the line is two inches per second. As a result, the other two values from the relationship among $\mathrm{N}$, $\mathrm{S}, \mathrm{v}, \mathrm{t}$, and R can be calculated as follow: (1) R is five, (2) the values of time matching with the determined numbers are 10 , $20,30,40$, and 50 seconds respectively

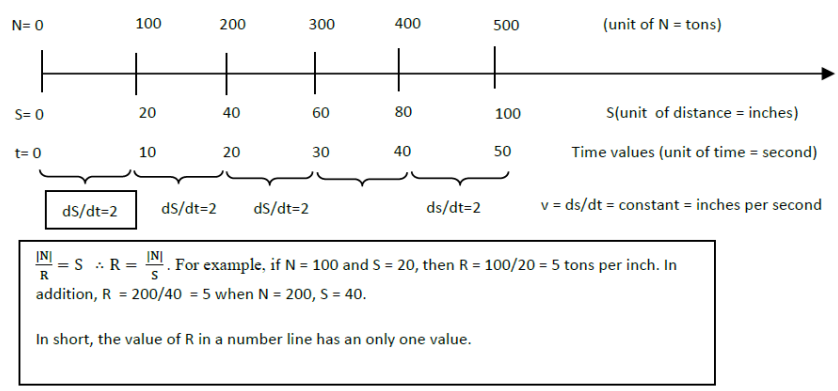

Fig. 1. The relationship among $S, v, N, R$, and $t$

\section{The time equation explaining equations in physics and economics}

Notably, the exact position of a value of time matching with a number in a number line can be calculated as follow: 


$$
\mathrm{t}=\frac{|\mathrm{N}|}{\mathrm{R} \cdot \mathrm{v}}=\frac{\mathrm{s}}{\mathrm{v}}=\mathrm{s}\left(\frac{\Delta \mathrm{t}}{\Delta \mathrm{S}}\right)
$$

For example, the first method by using $\mathrm{S}$ and v;

$$
\begin{aligned}
& t_{\text {at100 }}=\frac{S}{v}=\frac{20 \text { inches }}{2 \text { inches per second }}=\frac{20 \text { inches }}{\frac{2 \text { inches }}{1 \text { second }}}=10 \text { seconds } \\
& \text { The second method by using } \mathrm{N}, \mathrm{R} \text {, and } \mathrm{v} \text {; } \\
& R=\frac{|N|}{S \text { inches }}=\frac{\mid 100 \text { tons } \mid}{20 \text { inches }}=\frac{100 \text { tons }}{20 \text { inches }}=\frac{5 \text { tons }}{1 \text { inch }} \\
& t_{\text {at100 }}=\frac{|N|}{R \cdot v}=\frac{\mid 100 \text { tons } \mid}{(5 \text { tons per inch) }(2 \text { inches per second })}=\frac{100 \text { tons }}{\left(\frac{5 \text { tonj }}{1 \text { ingh }}\right)\left(\frac{2 \text { inches }}{1 \text { second }}\right)}=10 \text { seconds }
\end{aligned}
$$

Besides, the time equation (6), which can explain many equations in physics and economics, is real and well-founded [7]. The time equation is explaining the equations in physics such as $\mathrm{F}=\mathrm{mg}$ of Newton, $\mathrm{E}=\mathrm{mc}^{2}$ of Einstein, and $\mathrm{E}=\mathrm{h} v$ of Planck where E represents energy, h represents Plank's constant, and $v$ represents radiation frequency of an electromagnetic wave. Also, it is explaining the equations in economics as follow: (1) an equation of consumption or $\mathrm{C}=$ $\mathrm{C}_{\mathrm{a}}+\mathrm{MPC}\left(\mathrm{Y}_{\mathrm{d}}\right)$, where $\mathrm{C}$ represents consumption expenditure, $\mathrm{C}_{\mathrm{a}}$ represents autonomous consumption, MPC represents marginal propensity to consume, and $\mathrm{Y}_{\mathrm{d}}$ represents the disposable income of a country.

Second, an equation of saving or $S_{\text {ave }}=-S_{a}+\operatorname{MPS}\left(Y_{d}\right)$, where S represents saving, "- $S_{a}$ " represents dissaving, MPS represents marginal propensity to save, and $Y_{d}$ represents the disposable income of a country. The conclusion is the time equation explaining those equations in physics and economics as follows: $\mathrm{t}=\frac{\mathrm{F}}{\mathrm{Rvg}}, \mathrm{t}=\frac{\mathrm{E}}{\mathrm{Rvc}^{2}}, \mathrm{t}=\frac{\mathrm{E}}{\mathrm{Rvh}}, \mathrm{t}=\frac{\mathrm{LC}-\mathrm{C}_{\mathrm{a}} \mathrm{b}}{\mathrm{Rv}(\mathrm{MPC})}$, and

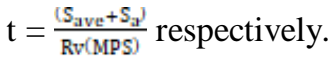

All of the equations in physics and economics consist of two main parts: dependent and independent variables. Usually, the independent variable will be determined as a horizontal axis that is a number line. The changing of the independent variable to be the determined number in time equation will be able to explain all equations by using the time equation. The time equation can explain the five equations in the following details [8].

There are four steps to use the time equation (6) explaining any linear equations. First, convert an equation to a function. For example, as it is depicted in Fig. 2, convert Newton's equation $(F=m g)$ to a function: $F=f(m)$. Second, solve the independent variable. For example, $\mathrm{F}=0+\left(\frac{\mathbb{A F}}{\mathbb{M m}}\right) \cdot \mathrm{m} ; \mathrm{F}=0+$ g.m; $\mathrm{m}=\frac{\mathrm{F}}{\mathrm{g}}$. Third, replace the determined number in the time equation with the independent variable. For example, $\frac{|\mathrm{m}|}{\mathrm{R}}=$ $\mathrm{S} ; \mathrm{S}=$ vt. Fourth, solve the time equation explaining the equation. For example, $\mathrm{m}=\mathrm{Rvt}$ and $\mathrm{t}=\frac{\mathrm{m}}{\mathrm{Rv}}=\mathrm{m}\left(\frac{1}{\mathrm{Rv}}\right)=\frac{\mathrm{F}}{\mathrm{Rvg}}$ . Time equation explaining equations in physics is in Table I.

An example of calculation in case of the time equation and Newton's equation is presented in Table II.

The time equation explaining equations in economics is illustrated in Table III.
Table I. time equation explaining equations in physics

\begin{tabular}{clcl}
\hline Step & $\begin{array}{l}\mathrm{F}=\mathrm{mg} \\
\text { of Newton }\end{array}$ & $\begin{array}{l}\mathrm{E}=\mathrm{mc}^{2} \\
\text { of Einstein }\end{array}$ & $\begin{array}{l}\mathrm{E}=\mathrm{h} v \\
\text { of Planck }\end{array}$ \\
\hline $\mathbf{1}$ & $\mathrm{F}=\mathrm{f}(\mathrm{m})$ & $\mathrm{E}=\mathrm{f}(\mathrm{m})$ & $\mathrm{E}=\mathrm{f}(v)$ \\
$\mathbf{2}$ & $\mathrm{m}=\mathrm{F} / \mathrm{g}$ & $\mathrm{m}=\mathrm{E} / \mathrm{c}^{2}$ & $v=\mathrm{E} / \mathrm{h}$ \\
$\mathbf{3}$ & $\frac{\mid \mathrm{m} /}{\mathrm{R}}=\mathrm{S}=\mathrm{vt}$ & $\frac{|\mathrm{m}|}{\mathrm{R}}=\mathrm{S}=\mathrm{vt}$ & $\frac{|\mathrm{F}|}{\mathrm{R}}=\mathrm{S}=\mathrm{vt}$ \\
$\mathbf{4}$ & $\mathrm{t}=\frac{\mathrm{F}}{\mathrm{Rvg}}$ & $\mathrm{t}=\frac{\mathrm{E}}{\text { Rvc }^{2}}$ & $\mathrm{t}=\frac{\mathrm{E}}{\mathrm{Rvh}}$
\end{tabular}

\begin{tabular}{|c|c|c|}
\hline $\mathrm{t}$ & $=$ & $\frac{F}{R v g}$ \\
\hline 3 & $=$ & $9.8 \times 30\left(\frac{900}{10}\right)\left(\frac{1}{100}\right)\left(\frac{1}{08}\right)$ \\
\hline $\mathrm{t}$ & $=$ & \\
\hline 3 & $=$ & (30) $\left(\frac{300}{30}\right)\left(\frac{3}{300}\right)$ \\
\hline $\mathrm{m}$ & $=$ & Rvt \\
\hline 30 & $=$ & $\left(\frac{90}{900}\right)\left(\frac{900}{9}\right) 3$ \\
\hline $\mathrm{F}$ & $=$ & Rvtg \\
\hline $9.8 \times 30$ & $=$ & $\left(\frac{90}{100}\right)\left(\frac{300}{9}\right)(3)(9.8)$ \\
\hline
\end{tabular}

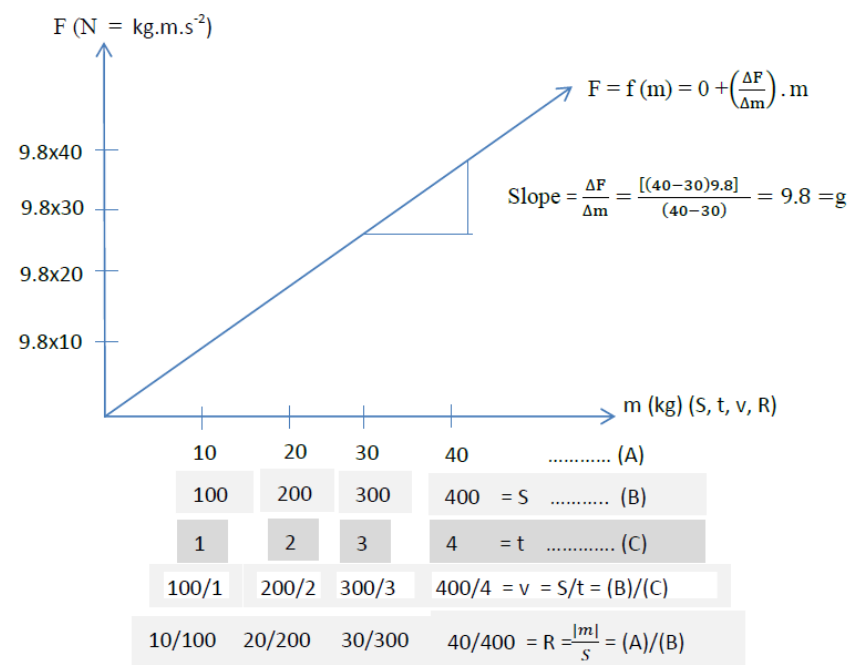

Fig. 2. The time equation explaining Newton's equation

Table II. An example of calculation in case of the time equation and Newton's equation

\begin{tabular}{|c|c|c|}
\hline 1 & $C=f\left(Y_{d}\right)$ & $S_{a v e}=f\left(Y_{d}\right)$ \\
\hline 2 & $\mathrm{Y}_{\mathrm{d}}=\mathrm{C}-\mathrm{C}_{\mathrm{a}} / \mathrm{MPC}$ & $\mathrm{Y}_{\mathrm{d}}=\mathrm{S}_{\mathrm{ave}}+\mathrm{S}_{\mathrm{a}} / \mathrm{MPS}$ \\
\hline 3 & $\frac{\left|Y_{i v}\right|}{\mathrm{R}}=\mathrm{S}=\mathrm{vt}$ & $\frac{Y_{\text {iv }}}{\mathrm{R}}=\mathrm{S}=\mathrm{vt}$ \\
\hline 4 & $\mathrm{t}=\frac{\mathrm{C}-\mathrm{C}_{\mathrm{a}}}{\operatorname{Rv}(\mathrm{M}(\mathrm{MPC})}$ & $\mathrm{t}=\frac{\mathrm{S}_{\mathrm{ave}}+\mathrm{S}_{\mathrm{J}}}{\operatorname{Rv}(\mathrm{MIPS})}$ \\
\hline
\end{tabular}

Table III. time equation explaining equations in economics

Step $\quad \mathrm{C}=\mathrm{C}_{\mathrm{a}}+$ MPC. $\mathrm{Y}_{\mathrm{d}} \quad \mathrm{S}_{\mathrm{ave}}=-\mathrm{S}_{\mathrm{a}}+$ MPS. $\mathrm{Y}_{\mathrm{d}}$ in macroeconomics in macroeconomics 


\section{CONCLUSION}

Mathematicians use numbers representing tangible and intangible things in nature. A time value always matches with a number (on a number line). As a result, time in numbers can connect the universes of science, social science, and all dimensions. All things are in the three-dimensional world that consists of a length, a width, and a thickness. Understanding the time dimension can open a new view for researchers to study the world of science and social science. Scientists always study the characteristics of things with the observation from outside of them first. They created their theories following what they saw or analyzed or experimented. Many theories in science such as physics and social science such as economics came from the deductive method, outside to inside such as a molecule to a particle. Studying of time came from the opposite paradigm of researching, the inductive method, and from inside to outside of things such as inside to outside a particle. Studying of time may increase the way for scientists studying science and social science to understand their worlds in different views.

Minkowski, for example, had analyzed that time was not in three principal axes before he created his mathematical model. His way of studying focused on his question "what should the time be?" In contrast, this paper focused on the question "what was the time?" and "where was it?" The investigation found that time always is in three principal axes. With different paradigms of studying, one of Minkowski's results such as the model of Light Cone is different from the result of this paper. Light from a source in nature shows a shape of sphere, not a cone following Minkowski's model.

The benefit of this study supports science, social science, and academic world. One of the theoretical problems in physics and economics is the same. In physics, quantum mechanics can be used well to explain what happens in the subatomic level. The theory could not work well when physicists used to explain phenomena in celestial world [5]. In economics, microeconomics can be used to explain what happens in many local markets. The theory could not work well when economists used to explain economic phenomena of a country which is in macroeconomics [9],[10]. Time may solve the problems inside theories of these subjects and solve many mysteries in science such as the strange of the shape of a pyramid and the characteristic of gravitational force soon.

In this paper, the time equation can explain the equations of physics and economics simultaneously. It showed itself as a missing link which physicists and economists have never found before. Usually, mathematicians need to have $\mathrm{N}$ equations for solving $\mathrm{N}$ variables. If researchers use the time equation to explain those $\mathrm{N}$ equations, then a time value can help them get at least $\mathrm{N}$ variables of $\mathrm{N}$ equations. The speed of calculation will increase that no one has seen before. The next characteristics of time and others in nature had just begun to show themselves in different views for researchers in academic world.

\section{REFERENCES}

1. "Hermann Minkowski Facts, information, pictures | Encyclopedia.com articles about Hermann Minkowski", Encyclopedia.com, 2016. [Online]. Available:

http://www.encyclopedia.com/topic/Hermann_Minkowski.aspx. [Accessed: 05- Sep- 2016].

2. S. Hawking, A brief history of time. New York: Bantam Books, 1998.

3. P. Davies, About time. New York: Simon \& Schuster, 1995.

4. M. Kaku, "The One-inch Equation to Explain All Physical Laws", Bigthink.com, 2016. [Online]. Available: http://bigthink.com/drkakus-universe/the-one-inch-equation-to-explain-all-physical-laws. [Accessed: 09- Sep- 2016].

5. M. Kaku and J. Trainer, Beyond Einstein. New York: Bantum Books, 1987, pp. 26-30.

6. P. Boonsri, "The study on time to develop an economic theory", in The 5th International Conference on Business and economics, Greece, 2014, pp. 186-197.

7. P. Boonsri, The Reseach on Linear Time Equation and the linkage to the Theory of Everything. Bangkok: BSRU, 2016.

8. P. Boonsri, "Advanced Linear time equation concerning with Michio Kaku one-inch eqaution", in National Conference on Management Science 2017, Faculty of Management Science of Bansondejchaopraya Rajabhat University, 2017, pp. 174-189.

9. P. Boonsri, "The time as the linkage between microeconomics and macroeconomics", in The 3rd International Conference on Production and Supply Chain Management, Spain, 2014, pp. 329-343.

10. P. Drucker, "Toward the Next Economics", in The Crisis in Economic Theory, 1st ed., D. Bell and I. Kristol, Ed. New York: Basic Books, 1981, pp. 4-18.

\section{Author Profile}

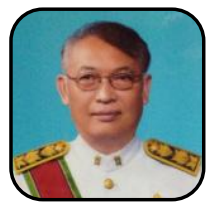

Poramest Boonsri was born and raised in Bangkok, Thailand and still lives in the thriving city today, with his wife and daughter. He attended the prestigious Faculty of Science at Khon Khen University, before going on to Ramkhamhaeng University where he attained a second-class honor in quantitative economics. Poramest has also obtained a master's degree in quantitative economics, an Australian's Diploma in Interdisciplinary Study and $\mathrm{PhD}$, the last coming from his research on a new price model in economics from Bansomdejchaopraya Rajabhat University, one of the oldest universities of Thailand. Poramest has been the Associate Professor in Economics of his university for many years and it was from this that he solved his incredible discovery in physics at Khon Kean University in 1987. This discovery was the turning point in his life and became the catalyst which inspired him to write many researching papers in three fields: (1) mathematics, (2) economics, and (3) physics, and a book on the subjects.Much of Poramest's writing career has centered on research papers and he is hoping that his book will be the inspiration that people need to become involved in sciences and the theories surrounding time. He is also planning another book called Quantitative Buddhist Economics.Amongst many honors bestowed upon him, Poramest is the recipient of The Most Noble Order of the Crown of Thailand from H.M King Rama IX of Thailand (2012) and The Most Exalted Order of the White Elephant, also from H.M King Rama IX of Thailand (2015). When he isn't working, Poramest loves nothing more than spending some quality time with his family, shopping or eating out with them. He also relaxes by practicing meditation, devotes some of his time to teaching English for Thai people free of charge. Poramest sees every obstacle as a stepping stone to success and it is his stated intention to stand present with peaceful mind as he goes towards the future. 